\title{
Silver nanoparticles incorporated PVC films: evaluation of structural, thermal, dielectric and catalytic properties
}

\author{
Ganesh Shimoga ${ }^{1}$ (D), Eun-Jae Shin ${ }^{1}$ (D) and Sang-Youn Kim* (D) \\ 'Interaction Laboratory of Advanced Technology Research Center, Korea University of Technology and \\ Education, Chungjeollo, Byeongcheon-Myeon, Cheonan City, South Korea \\ *sykim@koreatech.ac.kr
}

\begin{abstract}
In this work, silver nanoparticle - polyvinylchloride (SNC-PVC) composites were synthesized by loading $2.5 \%$ to $10.0 \%$ silver ions to PVC using simple solution casting technique. Material properties including dielectric, thermal stability were discussed in some detail. Incorporation of silver nanoparticles (SNPs) in the PVC matrix was confirmed by UV-Visible spectroscopy (UV-Vis), X-ray diffraction (XRD), Energy-dispersive X-ray spectroscopy (EDX) and Field Emission Scanning Electron Microscopy (FE-SEM). FE-SEM confirms the shape of the SNPs are roughly spherical with average size of the SNPs in the range of $60-80 \mathrm{~nm}$. The thermal degradation studies were analysed via sensitive graphical Broido's method using Thermogravimetric analysis (TGA). The resulting SNC-PVC films, especially with 10\% silver loading showed improved catalytic performance during the reduction of 4-nitrophenol (4-NP) to 4-aminophenol (4-AP) in the presence of aqueous sodium borohydride with apparent rate constant $1.956 \times 10^{-3} \mathrm{sec}^{-1}$ at ambient temperature.
\end{abstract}

Keywords: dielectric, heterogeneous catalysis, polyvinylchloride, silver nanocomposites, thermal analysis.

How to cite: Shimoga, G., Shin, E.-J., \& Kim, S.-Y. (2019). Silver nanoparticles incorporated PVC films: evaluation of structural, thermal, dielectric and catalytic properties. Polimeros: Ciência e Tecnologia, 29(3), e2019032. https:// doi.org/10.1590/0104-1428.08218

\section{Introduction}

Polymer nanocomposites provided exciting new insights in academia and industrial research ${ }^{[1-3]}$. There have been a great improvement in the synthesis of metal nanocomposites incorporated in fascinating polymer matrix and used in several practical applications ${ }^{[4,5]}$. Reinforcement of noble metal nanostructures into the polymer can improve the macroscopic properties of the bulk polymer, and the applications preceded to new directions ${ }^{[6,7]}$. From qualitative and quantitative point of view, the properties of nanoscale materials differ significantly in compare to those of bulk materials ${ }^{[8]}$. The remarkable change in physical and chemical properties including catalytic, electronic, and optical, can be observed with the reinforcement of nanosize materials into the bulk of the polymer matrix ${ }^{[9-11]}$. Among all the noble metal nanoparticles, nowadays silver nanoparticles are predominantly used in a wide range of potential applications in consumer products, electronic equipments, cancer treatment, medical imaging, drug delivery, and in the removal of organic pollutants from water (i.e. removal of nitro phenols by heterogeneous catalysis $)^{[12,13]}$.

There have been some successful attempts to develop varieties of polymer/copolymer matrices incorporated by SNPs and exploring their applications in industrial catalysis, hydrogen gas storage, toxic gas capture, water purification and etc ${ }^{[14,15]}$. Due to exceptional versatility and applicability, PVC is considered as one of the most widely used plastics in the global market. Also, excellent chemical stability, ease of modification and non flammability characters of PVC made them to use as a matrix for nanocomposites ${ }^{[16,17]}$.
The applications of PVC ranges from construction materials to health care, electronics, automobile and other industrial sectors ${ }^{[18-20]}$. Recently, Braga et al., reported the synthesis of SNPs incorporated PVC films with the silver loading of 1.0 to $8.0 \%$, the results revealed that the synthesized SNC-PVC composite films exhibited the highest antimicrobial activities and used for food packaging applications ${ }^{[21]}$. Thabet et al., reported incorporating clay and metal oxide nanoparticle fillers in the PVC can enhance the surface energy properties and tuned the dielectric properties for improved electronic applications ${ }^{[22]}$. To best of our knowledge, no systematic empirical research exists addressing the simple synthesis of SNC-PVC films for heterogeneous catalytic applications. In this work, simple solution casting method was adopted to fabricate SNC-PVC composite films with preferred thickness by reducing silver ions to SNPs using ecofriendly trisodium citrate dihydrate solution. Thermal degradation of SNC-PVC composite films were systematically characterized using TGA and a sensitive graphical Broido'd method ${ }^{[23]}$ was used to characterize each degradation steps. The variation of dielectric properties (dielectric constant and loss factor) were measured using impedance analyzer. Morphology of SNC-PVC films are examined using FE-SEM, which exemplifies homogeneous distribution of silver nanoparticles in the PVC matrix and are roughly spherical with size of SNPs in the range of 60-80 nm. SNC-PVC composite films were subjected to catalytic performances for the reduction of 4-nitrophenol to 4-aminophenol in presence of sodium borohydride and the results were reported. 


\section{Materials and Methods}

\subsection{Materials}

Silver nitrate, polyvinylchloride ( $\mathrm{Mw} \sim 233000$ ), and trisodium citrate dihydrate were procured from Sigma Aldrich, Seoul, South Korea. All the other chemicals and solvents are of reagent grade and used without any further purification. Double distilled HPLC grade water was used throughout the study.

\subsection{SNC-PVC Nanocomposite films preparation}

PVC films doped with silver (II) nitrate $\left(\mathrm{AgNO}_{3}\right)$ in various concentrations were prepared at room temperature by simple solution casting method. The desired concentration of silver nitrate solutions (2.5, 5.0, 7.5 and 10.0 weight $\%)$ were prepared by using cold distilled water $(400-800 \mu \mathrm{L})$. PVC (1g) was dissolved in $20 \mathrm{~mL}$ tetrahydrofuran (THF) at room temperature $\left(22^{\circ} \mathrm{C}\right)$, a known amount silver nitrate solutions were loaded into the polymer solutions separately (For Ag-PVC-2.5, $25 \mathrm{mg}$ of silver nitrate was dissolved in $500 \mu \mathrm{L}$ of water and loaded to $1 \mathrm{~g}$ of PVC solution in $25 \mathrm{~mL}$ of THF). The solution was stirred for $10 \mathrm{~h}$ at room temperature and the resulting homogeneous solution was cast onto a glass plate with the aid of a casting knife. The thin films were allowed to dry at room temperature for $72 \mathrm{~h}$ and vacuum dried at $50^{\circ} \mathrm{C}$ for $10 \mathrm{~h}$, the completely dried films were subsequently peeled off. The stoichiometric mass ratio of silver nitrate with respect to PVC was varied as $0.0,2.5,5.0,7.5$ and 10.0 , and the resulting thin films were designated as PVC, Ag-PVC-2.5, Ag-PVC-5.0, Ag-PVC-7.5 and Ag-PVC-10.0, respectively. The thickness of the thin films was measured at different points using peacock dial thickness gauge (Model G, Ozaki MFG. Co. Ltd., Japan) with an accuracy of $\pm 2 \mu \mathrm{m}$ and the average thickness was considered for calculation. The thickness of the membranes was found to be $350 \pm 2 \mu \mathrm{m}$.

The $\mathrm{Ag}^{+2}$ doped PVC films (Ag-PVC-2.5, Ag-PVC-5.0, Ag-PVC-7.5 and Ag-PVC-10.0) were cut in to the dimensions of $250 \mathrm{~mm} \times 250 \mathrm{~mm}$ and suspended in $50 \mathrm{~mL}$ of $1 \mathrm{mM}$ solution of trisodium citrate solution for $30 \mathrm{~min}$ with gentle stirring. The obtained SNC-PVC composite films were washed repeatedly with distilled water, gently wiped with clothing tissue paper and vacuum dried at $50{ }^{\circ} \mathrm{C}$ for $10 \mathrm{~h}$. The resulting composite films were designated as SNC-PVC-2.5, SNC-PVC-5.0, SNC-PVC-7.5 and SNC-PVC-10.0, respectively.

\subsection{Catalytic reduction of 4-nitrophenol (4-NP) to 4-aminophenol (4-AP)}

Catalytic performance of SNC-PVC-10.0 was evaluated for the model reduction reaction of 4-NP to 4-AP in a standard $10 \mathrm{~mL}$ quartz cell. Typically, $10 \mathrm{~mL}$ of aqueous 4-NP $(0.1 \mathrm{mM})$ solution was mixed with $0.05 \mathrm{~g}$ of SNC-PVC-10.0, followed by the addition of $5 \mathrm{~mL}$ aqueous $\mathrm{NaBH}_{4}$ solution $(50 \mathrm{mM})$, and the time dependent UV-vis absorption spectra was recorded by VARIANEL08043361 UV- vis spectrophotometer (Varian, USA). the conversion of 4-NP to 4-AP processes was monitored every $5 \mathrm{~min}$ interval in a scanning range from 250 to $600 \mathrm{~nm}$ at room temperature $\left(22^{\circ} \mathrm{C}\right)$.
The percentage catalytic convertion efficiency of 4-NP into 4-AP was calculated by the following Equation (1):

$$
\text { Percentage }(\%) \text { conversion }=\frac{C_{0}-C_{t}}{C_{0}}
$$

where $C_{t}$ is the concentration of 4-NP measured at time t, $C_{0}$ is the initial concentration of 4-NP measured at time zero ${ }^{[24,25]}$.

\subsection{Instrumentation}

SNC-PVC composite films were investigated using solid state electronic absorption spectra on a Perkin-Elmer UV-Vis spectrometer, model UV/VIS-35 (PerkinElmer, Inc., MA, USA). To understand the effect of doping of $\mathrm{Ag}^{+2}$ and SNPs content in PVC, thin films were subjected to powder X-ray diffraction study using Brucker's D-8 advanced X-ray diffractometer. The X-ray source was $\mathrm{Ni}$ filtered $\mathrm{Cu} \mathrm{K} \alpha$ radiation. The diffraction was scanned in the reflection mode at an angle $2 \theta$ over a range of 5 to $90^{\circ}$ at a constant speed of $8 \% \mathrm{~min}$. Similarly, the surface morphology of PVC silver nanocomposites were analyzed by using Ultra-High-Resolution Field-Emission Scanning Electron Microscope (FESEM, FEI, \& Nova NanoSEM450) instrument operating at $25 \mathrm{kV}$. Thermal stability of SNC-PVC films were investigated using thermogravimetric analyzer (Q500, TA instruments, DE, USA) in the range from $25^{\circ} \mathrm{C}$ to $600^{\circ} \mathrm{C}$ in a $50 \mathrm{~mL} / \mathrm{min}$ flow of $\mathrm{N}_{2}$ gas at a heating rate of $10^{\circ} \mathrm{C} / \mathrm{min}$. SNC-PVC composite films were subjected to the dielectric measurements; samples were sandwiched between two gold plated electrodes and analysed by impedance analyzer, model HIOKI 3352-50 HiTESTER Version 2.3. The electrical contacts were checked to verify the ohmic connection. The measurements were carried out at room temperature in between the $50 \mathrm{~Hz}-5 \mathrm{MHz}$. The dielectric constant ( $\left.\varepsilon^{\prime}\right)$ was calculated using Equation (2) and dielectric $\operatorname{loss}(\tan \delta)$ was calculated using Equation (3).

$$
\begin{aligned}
& \varepsilon^{\prime}=\left(C_{p} d\right) /\left(\varepsilon_{o} A\right) \\
& \tan \delta=\varepsilon^{\prime \prime} / \varepsilon^{\prime}
\end{aligned}
$$

where ' $d$ ' is the thickness of the polymer film and ' $A$ ' is the cross-section area, ' $\varepsilon_{0}$ ' is the permittivity of the free space, ' $\varepsilon$ '' and ' $\varepsilon$ ' ' is the permittivity (imaginary part) and permittivity (real part) of the material respectively. All these measurements were performed under dynamic vacuum.

\section{Results and Discussions}

\subsection{Characterization of SNC-PVC nanocomposite films}

Solid state UV-Vis spectroscopy was performed for Ag-PVC-10.0 and SNC-PVC-10.0 thin films. As can be seen in Figure 1 (a), spectra confirms the characteristic surface plasmon resonance band for SNC-PVC-10.0, which was observed in the range of $440-460 \mathrm{~nm}$, confirms the formation of SNPs on the PVC matrix.

Figure 1 (b) shows the XRD pattern of PVC, Ag-PVC-10.0 and SNC-PVC-10.0. The diffraction peaks of PVC locate at $17.2^{\circ}$ and $24.5^{\circ}$, which was the characteristic pattern of PVC. 
A low percolation threshold of $\mathrm{Ag}^{+}$doping to the bulk PVC was found in the pattern of Ag-PVC-10.0. The crystalline nature of the SNPs was confirmed for SNC-PVC-10.0 by the arrival of $2 \theta$ values at $38.2^{\circ}, 44.8^{\circ}, 64.3^{\circ}, 76.8^{\circ}$ and $82.6^{\circ}$ for characteristic crystal planes (111), (200), (220), (311) and (222) respectively ${ }^{[26]}$.

The FE-SEM of all the SNC-PVC composite surfaces are displayed in Figure 2 (a) to (d) and EDX spectrum of
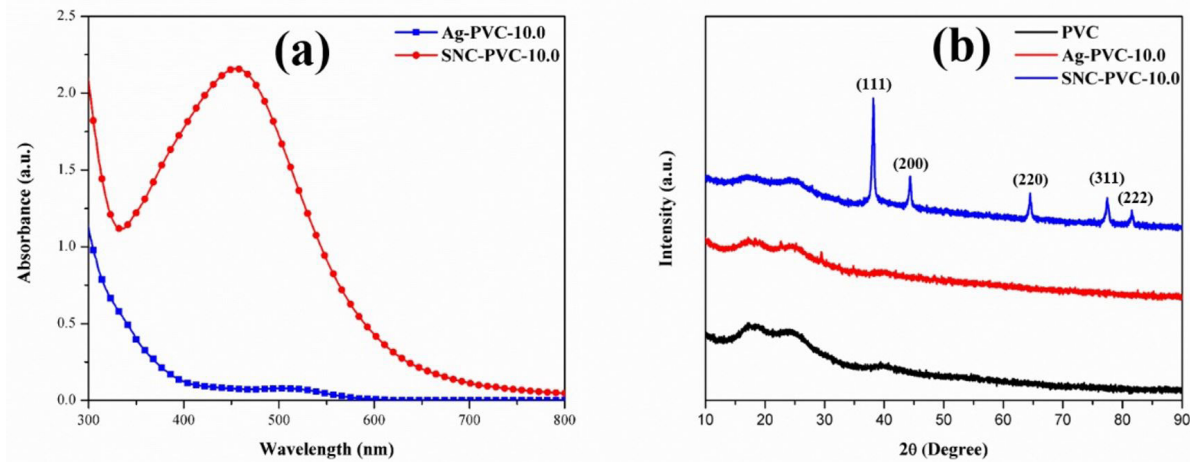

Figure 1. (a) Solid state UV-Vis spectra of Ag-PVC-10.0 and SNC-PVC-10.0 films (b) XRD pattern of PVC, Ag-PVC-10.0 and SNC-PVC-10.0 films.

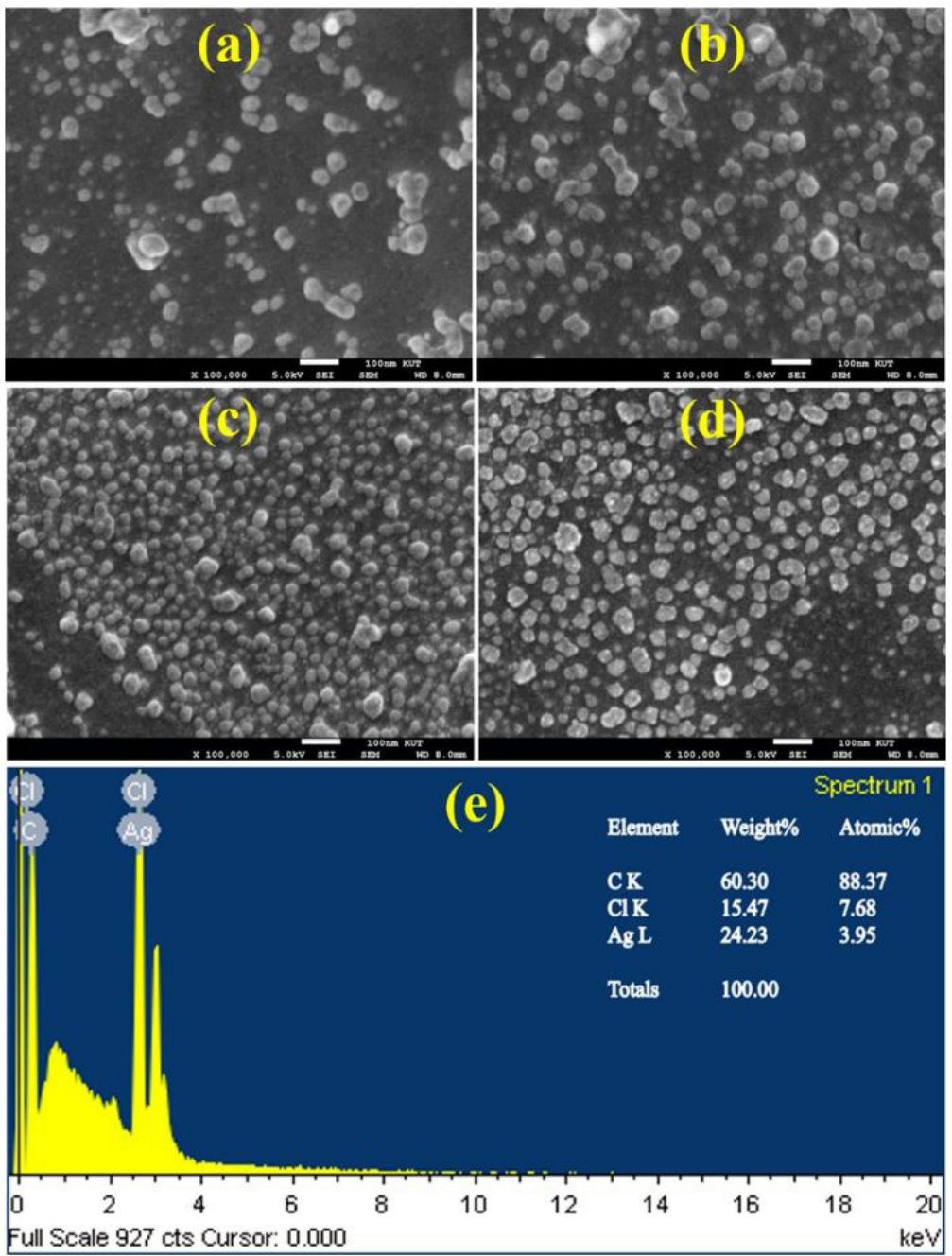

Figure 2. FE-SEM micrograph of (a) SNC-PVC-2.5 surface (b) SNC-PVC-5.0 surface (c) SNC-PVC-7.5 surface (d) SNC-PVC-10.0 surface (e) EDX Spectrum of SNC-PVC-10.0. 
SNC-PVC-10.0 was displayed in Figure 2 (e), The surface morphology for SNC-PVC-2.5 and SNC-PVC-5.0 were shown in Figure 2 (a) and (b) respectively, from which the average size of the SNPs were found to be distributed in the range of $20 \mathrm{~nm}$ to $140 \mathrm{~nm}$, it seems that the size of the SNPs are not uniform. Where as, from the Figure 2 (d) and (e), the surface morphology of SNC-PVC-7.5 and SNC-PVC-10.0 were seems to be uniform and roughly spherical in shape with average size of the SNPs distributed in the range of 60-80 nm. Elemental composition analysis by EDX presented in Figure 2 (e), which shows strongest signal near to $3 \mathrm{keV}$, which is the typical absorption pattern of metallic nanocrystalline silver surface, also strongest signals for carbon and chlorine atoms of PVC were obtained it indicates the presence of SNPs in PVC matrix.

The average particle size, size distribution of SNC-PVC films in colloidal THF suspensions were evaluated by using dynamic light scattering (DLS) experiments. It measures the Brownian motion and relates this to the size of the particles. The nanosize measurements were performed using the Zetasizer (Nano ZS, Malvern, UK). Each SNC-PVC composite films $(100 \mathrm{mg})$ were dissolved in $100 \mathrm{~mL}$ of THF and the measurement was repeated in triplicate at a fixed angle of $173^{\circ}$ at $22^{\circ} \mathrm{C}$. Representative histogram displayed in Figure 3 (a) (b) (c) and (d), showed that the particles are distributed in the range of $20-140 \mathrm{~nm}$ and majority of the particles are in the range of $60-80 \mathrm{~nm}$. This was further evidenced by FESEM analysis.
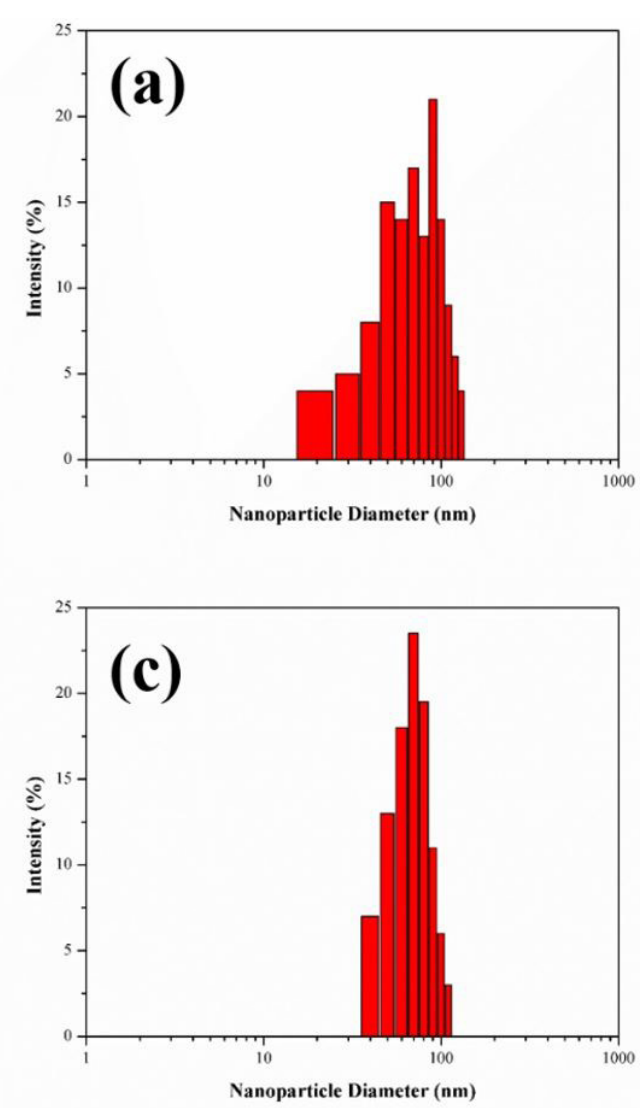

From the TG plot shown in Figure 4 (a), it was observed that the thermogram of PVC and SNC-PVC showed two major degradation steps with onset decomposition at $240{ }^{\circ} \mathrm{C}$. But, PVC suffers the degradation at $90{ }^{\circ} \mathrm{C}$ due to trapped THF molecules inside the PVC chains. The initial weight loss step started at around $240-415^{\circ} \mathrm{C}$ was attributed to the dehydrochlorination in the PVC chains, leading to the formation of long sequences of polyenes. Second degradation step is in the range of $415-475^{\circ} \mathrm{C}$ can be accounted for the main PVC chains with conjugated double bonds resulted from dehydrochlorination ${ }^{[27,28]}$.

However, PVC had a initial slight reduced thermal stability due to trapped THF solvent inside the PVC chains, because of this PVC suffers degradation below $100{ }^{\circ} \mathrm{C}$. Practical weight loss in PVC was observed with onset decomposition at $240^{\circ} \mathrm{C}$, and slight thermal stability of SNC-PVC compare to PVC was due to the SNPs covering the PVC surface. which resists partially for the better diffusion of hydrocholoric acid $(\mathrm{HCl})$ gas produced during dehydrochlorination of PVC. Kinetic and thermodynamic parameters were calculated using Broido's method ${ }^{[21]}$. Broido has developed a model and the activation energy associated with each stage of decomposition and was evaluated by this method ${ }^{[29]}$.

Plots of $-\ln (\ln (-1 / y))$ versus $1 / T$ (Figures $4($ b), $4(c)$ and $4(d)$ ) were developed for the decomposition segments of PVC and SNC-PVC films. From the plots, the activation energy $\left(E_{a}\right)$ and frequency factor $(\ln A)$ were evaluated. The enthalpy $(\Delta H)$, entropy $(\Delta S)$, and free energy $(\Delta G)$ have been calculated
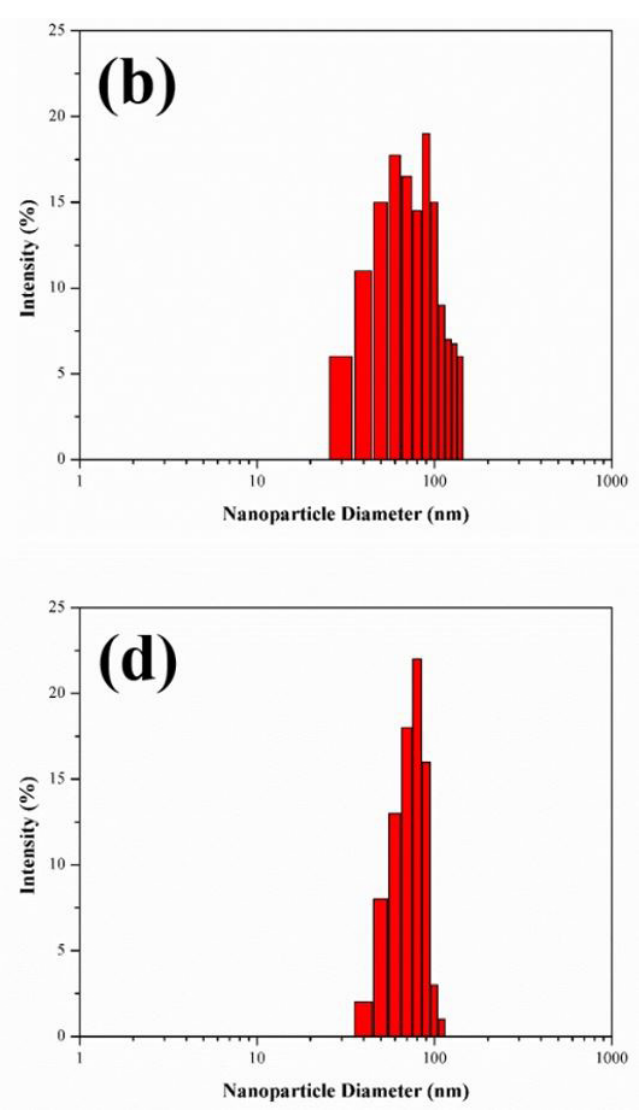

Figure 3. Histogram of particle size distribution of (a) SNC-PVC-2.5 (b) SNC-PVC-5.0 (c) SNC-PVC-7.5 (d) SNC-PVC-10.0. 

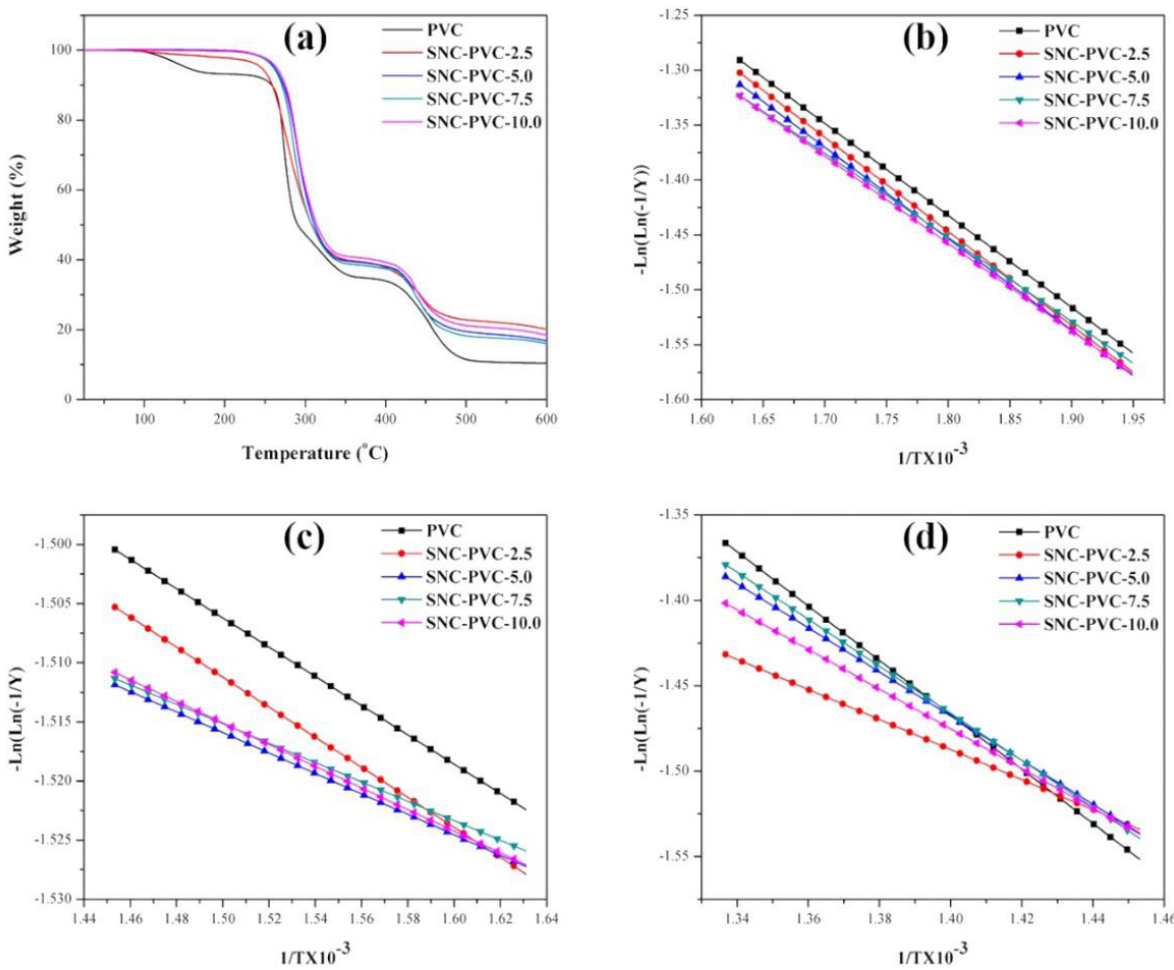

Figure 4. (a) TG analysis of PVC and SNC-PVC films (b) Plots of $-\operatorname{Ln}(\ln (-1 / y))$ vs $1 / T \times 10^{-3}$ for the first decomposition step in the range $240-340{ }^{\circ} \mathrm{C}$ (c) Plots of $-\operatorname{Ln}(\ln (-1 / \mathrm{y}))$ vs $1 / \mathrm{T} \times 10^{-3}$ for the decomposition step in the range $340-415^{\circ} \mathrm{C}(\mathrm{d}) \mathrm{Plots}$ of $-\operatorname{Ln}(\ln (-1 / \mathrm{y}))$ vs $1 / \mathrm{T} \times 10^{-3}$ for the second decomposition step in the range $415-475^{\circ} \mathrm{C}$.

Table 1. Kinetic and thermodynamic parameters of PVC and SNC-PVC at the decomposition range $240-340{ }^{\circ} \mathrm{C}$.

\begin{tabular}{cccccc}
\hline Title & $\begin{array}{c}\mathbf{E}_{\mathbf{a}} \\
(\mathbf{k J} / \mathbf{m o l}) \\
\mathbf{x ~ 1 0}\end{array}$ & $\mathbf{l n} \boldsymbol{A}$ & $\begin{array}{c}\Delta \mathbf{H} \\
(\mathbf{k J} / \mathbf{m o l})\end{array}$ & $\begin{array}{c}\Delta \mathbf{S} \\
(\mathbf{k J} / \mathbf{K})\end{array}$ & $\begin{array}{c}\Delta \mathbf{G} \\
(\mathbf{k J} / \mathbf{m o l})\end{array}$ \\
\hline PVC & 16.031 & -6.551 & -4.665 & -160.214 & 90.200 \\
SNC-PVC-2.5 & 14.642 & -6.787 & -4.666 & -161.565 & 90.961 \\
SNC-PVC-5.0 & 15.926 & -6.635 & -4.665 & -162.066 & 91.243 \\
SNC-PVC-7.5 & 16.382 & -6.555 & -4.664 & -161.532 & 90.942 \\
SNC-PVC-10.0 & 16.382 & -6.555 & -4.664 & -161.532 & 90.942 \\
\hline
\end{tabular}

Table 2. Kinetic and thermodynamic parameters of PVC and SNC-PVC at the decomposition range $340-415^{\circ} \mathrm{C}$.

\begin{tabular}{cccccc}
\hline Title & $\begin{array}{c}\mathbf{E}_{\mathbf{a}} \\
(\mathbf{k J} / \mathbf{m o l}) \\
\mathbf{x ~ 1 0}\end{array}$ & $\mathbf{l n} \boldsymbol{A}$ & $\begin{array}{c}\Delta \mathbf{H} \\
(\mathbf{k J} / \mathbf{m o l})\end{array}$ & $\begin{array}{c}\Delta \mathbf{S} \\
(\mathbf{k J} / \mathbf{K})\end{array}$ & $\begin{array}{c}\Delta \mathbf{G} \\
(\mathbf{k J} / \mathbf{m o l})\end{array}$ \\
\hline PVC & 1.368 & -9.489 & -5.406 & -162.580 & 105.760 \\
SNC-PVC-2.5 & 1.433 & -9.464 & -5.406 & -162.742 & 105.865 \\
SNC-PVC-5.0 & 1.657 & -9.911 & -5.406 & -162.792 & 105.898 \\
SNC-PVC-7.5 & 1.671 & -9.969 & -5.407 & -162.761 & 105.878 \\
SNC-PVC-10.0 & 1.752 & -9.847 & -5.406 & -162.782 & 105.891 \\
\hline
\end{tabular}

Table 3. Kinetic and thermodynamic parameters of PVC and SNC-PVC at the decomposition range $415-475^{\circ} \mathrm{C}$.

\begin{tabular}{cccccc}
\hline Title & $\begin{array}{c}\mathbf{E}_{\mathbf{a}} \\
(\mathbf{k J} / \mathbf{m o l}) \\
\mathbf{x ~ 1 0}\end{array}$ & $\mathbf{l n} \boldsymbol{A}$ & $\begin{array}{c}\Delta \mathbf{H} \\
(\mathbf{k J} / \mathbf{m o l})\end{array}$ & $\begin{array}{c}\Delta \mathbf{S} \\
(\mathbf{k J} / \mathbf{K})\end{array}$ & $\begin{array}{c}\Delta \mathbf{G} \\
(\mathbf{k J} / \mathbf{m o l})\end{array}$ \\
\hline PVC & 30.465 & -4.447 & -5.939 & -160.989 & 115.594 \\
SNC-PVC-2.5 & 16.853 & -6.228 & -5.953 & -161.327 & 115.837 \\
SNC-PVC-5.0 & 22.718 & -5.138 & -5.945 & -160.645 & 115.347 \\
SNC-PVC-7.5 & 24.363 & -4.936 & -5.943 & -160.757 & 115.427 \\
SNC-PVC-10.0 & 26.233 & -5.469 & -5.947 & -160.894 & 115.526 \\
\hline
\end{tabular}


using standard equations and are summarized in Tables 1 , Tables 2 and Tables 3 .

The results indicated in Table 1, the activation energies for SNC-PVC-2.5 and SNC-PVC-5.0 compared to PVC, SNC-PVC-7.5 and SNC-PVC-10.0 are lower, signposting that the decomposition step is faster in case of SNC-PVC-2.5 and SNC-PVC-5.0. Similarly, from the Table 2. it reveals that, gradual increase in the activation energy of PVC to SNC-PVC-10.0 indicates the thermal stability of SNC-PVC composite films over the temperature range $340-415^{\circ} \mathrm{C}$. From the Table 3 . we can easily recognize that the rate of second major degradation step in the decomposition range $415-475^{\circ} \mathrm{C}$ of PVC was comparibly slower to their respective SNC-PVC composite films. This is due to the presence of $\mathrm{Ag}^{+}$and nitrate ions in the vicinity of PVC chains. During the reduction process of $\mathrm{Ag}^{+}$ions by trisodium citrate solution, more $\mathrm{Ag}^{+}$ions on the surface of PVC was reduced for form SNPs. Since the formation of SNPs on the surface of SNC-PVC samples from 2 weight $\%$ to 10 weight $\%$ increases, due to the reduction of more $\mathrm{Ag}^{+}$ions on the surface. The stability of SNC-PVC films gradually increses from 2 weight $\%$ to 10 weight $\%$, consequently the rate of decomposition is slower with the increase of SNPs on the surface of SNC-PVC composite films.

The plot of variation of dielectric constant as a function of $\log$ (frequency) at room temperature is shown in Figure 5 (a). The plot illustrates that it is generally followed by almost all the dielectric and ferroelectric materials. The dielectric constant drops at high frequencies; this is due to the fact that the dipoles can no longer follow the high frequencies; the dielectric constant of 2.2 is achieved for SNC-PVC-2.5. In the middle frequency region the dielectric constant is approximately constant for all SNC-PVC and PVC films except SNC-PVC-2.5. Minimum dielectric constant value of 1.22 was obtained for SNC-PVC-10.0.

Higher the content of SNPs in the PVC matrix upshot the lower dielectric constant and it may also be due to affecting factor of restricted motion of SNPs. Also, increasing of the frequencies cause decreasing of space charge polarization (interfacial polarization) to the total polarization ${ }^{[30]}$. At lower frequencies, this interfacial polarization is most contributing type of polarization, and less contributing with the increase of frequency; this caused the decreasing of dielectric constant values for increasing the SNPs.

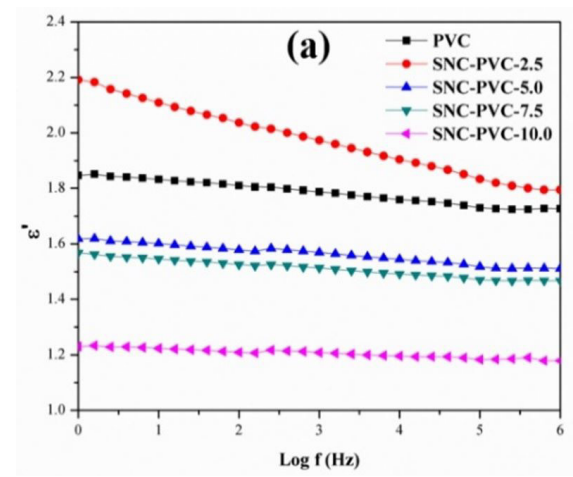

Frequency dependence variations of dielectric loss at room temperature were presented in Figure 5 (b). As per the plot, $\tan \delta$ decreases with increase of frequency and attains the constant value. The dielectric loss of all composite films are lower than 0.08 ; at $1.5 \log \mathrm{F}(\mathrm{Hz})$ values, $\tan \delta$ was well below 0.05 and maintaining the constant value. But the SNC-PVC-2.5 films display higher dielectric loss compared to other SNC-PVC films, which is due to high ion drifting and freedom of movement in dipole polarisation ${ }^{[31,32]}$ due to the available free space for SNPs with respect to PVC.

\subsection{Catalytic activity}

The catalytic performance of SNC-PVC-10.0 was investigated for the aqueous reduction of 4-NP to 4-AP in the presence of $\mathrm{NaBH}_{4}$ as a model reaction was depicted in Figure 6 (a). After the addition of $50 \mathrm{mM}$ aqueous solution of $\mathrm{NaBH}_{4}$ to the aqueous 4-NP solution, the light yellow color of 4-NP solution changed to intense yellow, due to the immediate formation of sodium phenolate. The reaction was not proceeded without the addition of SNC-PVC- 10.0 catalyst even after 9 days of monitering by UV-Vis spectroscopy. Also, the visible persistence of yellow color confirms very slow conversion rate of 4-NP into 4-AP. Addition of finely chopped $(1 \mathrm{~mm} \times 10 \mathrm{~mm})$ SNC-PVC-10.0 films into the mixture of aqueous 4-NP and $\mathrm{NaBH}_{4}$ solution, drastically changes the rate of reaction. The intense yellow color the reaction mixture (aqueous 4-NP and $\mathrm{NaBH}_{4}$ solution) was diminished to colorless in $25 \mathrm{~min}$ (Table 4).

The catalytic reaction was monitored by time dependant UV-visible spectrophotometer and also by visual appearance. The mechanism involved in the reduction reaction can be explained as follows: initialy, $\mathrm{BH}_{4}^{-}$ions reacts with SNPs present on the surface of PVC matrix to form silver hydride, the formed silver hydrides reacts with nitro $\left(-\mathrm{NO}_{2}\right)$ groups to convert it into amino $\left(-\mathrm{NH}_{2}\right)$ groups. The electron transfer from donor $\left(\mathrm{BH}_{4}^{-}\right.$ions) to acceptor (4-NP ions) was facilitated by SNC-PVC-10.0 (heterogeneous solid catalyst). Figure 6 (b), shows the characteristic time dependant absorption peak at $400 \mathrm{~nm}$ and $300 \mathrm{~nm}$ for 4-NP and 4-AP respectively.

SNC-PVC-10.0 composite films shows appreciable catalytic performances for the model reduction reaction of 4-NP. Esumi et al. ${ }^{[33]}$ in 2004, reported the catalytic activities of silver, platinum and palladium composites of

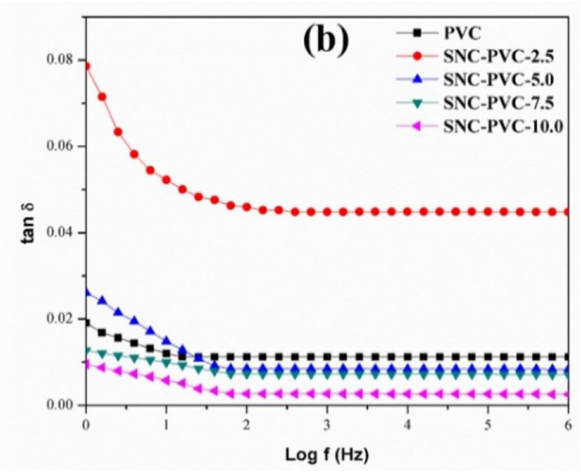

Figure 5. Room temperature variation of (a) dielectric constant (b) dielectric loss with log (frequency) for PVC and SNC-PVC nanocomposite films. 

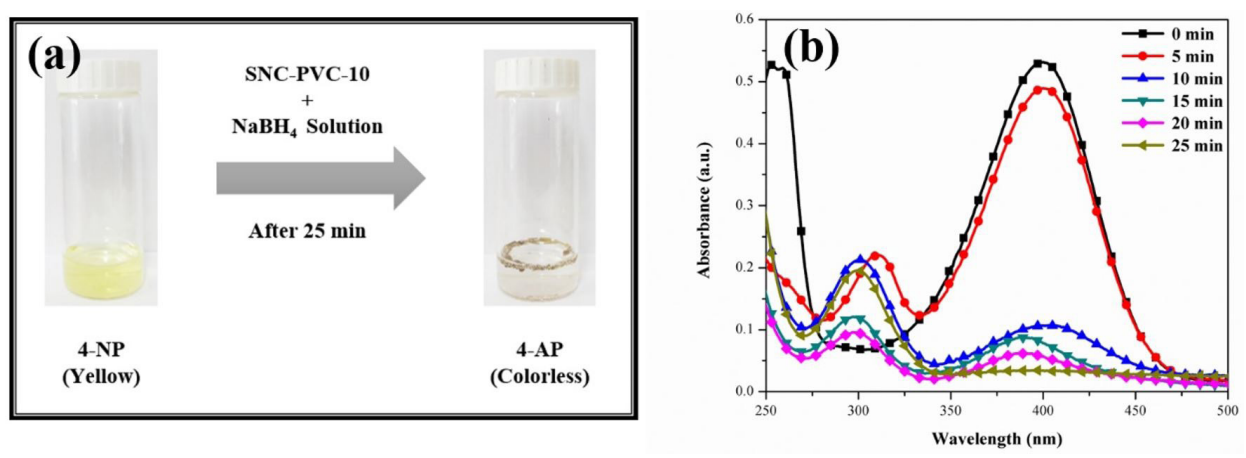

Figure 6. (a) Pictograph representing the catalytic reduction of 4-NP into 4-AP by SNC-PVC-10.0 (b) Time dependant UV-Vis spectra representing the catalytic reduction of 4-NP into 4-AP in aqueous medium in the presence of $5 \mathrm{mg} \mathrm{mL}^{-1} \mathrm{SNC}-\mathrm{PVC}-10.0[(4-\mathrm{NP}=0.1 \mathrm{mM})$, $\left.\left(\mathrm{NaBH}_{4}=50 \mathrm{mM} ; 22^{\circ} \mathrm{C}\right)\right]$.

Table 4. Catalytic reduction of 4-NP to 4-AP using SNC-PVC-10.0 films.

\begin{tabular}{cc}
\hline Time (min) & \% Conversion of 4-NP to 4-AP \\
\hline 0 & 0 \\
5 & 7.948 \\
10 & 79.374 \\
15 & 83.970 \\
20 & 88.152 \\
25 & 94.085 \\
\hline
\end{tabular}

poly(amidoamine) and poly(propyleneimine) dendrimenrs, the apparent rate constant $\left(k_{A P P}\right)$ reported was $5.9 \times 10^{-4} \mathrm{sec}^{-1}$ and $1.22 \times 10^{-3} \mathrm{sec}^{-1}$ respectively. The value reported by Chang et al. ${ }^{[25]}$ for polypyrrole encased SNPs was $1.1 \times 10^{-3} \mathrm{~s}^{-1}$. Murugan et al. ${ }^{[34]}$ reported solid catalysts composed of polystyrene functionalized with polyvinylimidazole immobilized SNPs with $k_{A P P}=5.12 \times 10^{-4} \mathrm{~s}^{-1}$. The apparent rate constant $\left(k_{A P P}\right)$ calculated from our study using PVC as polymer matrix was $1.956 \times 10^{-3} \mathrm{sec}^{-1}$, which was comparatively higher than the reported values from the literature for same catalytic reduction reaction by polymer supported SNPs. Also, it was considerably close to the value $2.12 \times 10^{-3} \mathrm{sec}^{-1}$ for SNPs encapsulated amphiphilic copolymer micelles of poly(2-ethyl-2-oxazoline) and poly( $\varepsilon$-caprolactone)s reported by Safari et al. ${ }^{[12]}$.

\section{Conclusions}

In summary, SNC-PVC films of silver doping from 2.5 to $10.0 \%$ (stochiometric) were successfully prepared using simple solution casting technique. The thermal stability of all the composites films were studied using TGA. The sensitive graphical Broido's method was employed to study the thermodynamical parameters at each stage of thermal degradation steps. The SNPs on the PVC surface was confirmed by UV-Vis, XRD, EDX. The SNPs on SNC-PVC-10.0 were studied using FE-SEM and DLS measurements, it was found that SNPs were uniformly distributed with size in the range of 60-80 nm. EDX elemental composition at any place of the SNC-PVC films clears the uniform distribution of SNPs on the PVC surface. It was noted that, the thermal stability of SNC-PVC films are increased from 2.5 weight $\%$ to 10 weight $\%$, confirming that positive effect on the thermal stability of the SNC-PVC films. Dielectric studies of all SNC-PVC films were performed using impedance analyser, it was found that dielectric constant and loss factor for all the composites were reduced drastically at higher content of SNPs loading due to either reduced atomic polarizability or density within the SNC-PVC films ${ }^{[35]}$. The article also highlights the catalytic performances of a model reduction reaction of 4-NP using aqueous $\mathrm{NaBH}_{4}$ solution. The catalytic reaction in the first and second run starts immediately after the addition of $\mathrm{NaBH}_{4}$ to 4-NP solution with SNC-PVC-10.0. So the catalytic performances of SNC-PVC-10.0 was briefly studied out of all SNC-PVC composites. The calculated apparent rate constant for SNC-PVC-10.0 was $1.956 \times 10^{-3} \mathrm{sec}^{-1}$ at ambient temperature. Our results show that these SNC-PVC-10.0 composites are highly recommeded as nanocatalysts and ideal materials as heterogeneous catalysts to demonstrate their potential applications in industrial catalysis ${ }^{[36]}$, also tenability of dielectric properties of these materials opens up sensing and electronic applications including microelectronics ${ }^{[37]}$.

\section{Acknowledgements}

This work was supported by the Technology Innovation Program (10077367, Development of a film-type transparent /stretchable 3D touch sensor /haptic actuator combined module and advanced UI/UX) funded by the Ministry of Trade, Industry \& Energy (MOTIE, Korea). This work was also supported by Priority Research Centers Program through the National Research Foundation of Korea (NRF) funded by the Ministry of Education (NRF-2018R1A6A1A03025526). Thanks for Cooperative Equipment Center at KoreaTech for assistance with UV-Vis, TGA, DLS, XRD, FESEM analysis.

\section{References}

1. Dzhardimalieva, G. I., \& Uflyand, I. E. (2018). Preparation of metal-polymer nanocomposites by chemical reduction of metal ions: functions of polymer matrices. Journal of Polymer Research, 25(12), 255. http://dx.doi.org/10.1007/s10965-0181646-8. 
2. Hussain, F., Hojjati, M., Okamoto, M., \& Gorga, R. E. (2006). Review article: polymer-matrix nanocomposites, processing, manufacturing, and application: an overview. Journal of Composite Materials, 40(17), 1511-1575. http://dx.doi. org/10.1177/0021998306067321.

3. Müller, K., Bugnicourt, E., Latorre, M., Jorda, M., Echegoyen Sanz, Y., Lagaron, J. M., Miesbauer, O., Bianchin, A., Hankin, S., Bölz, U., Pérez, G., Jesdinszki, M., Lindner, M., Scheuerer, Z., Castelló, S., \& Schmid, M. (2017). Review on the processing and properties of polymer nanocomposites and nanocoatings and their applications in the packaging, automotive and solar energy fields. Nanomaterials (Basel, Switzerland), 7(4), 74. http://dx.doi.org/10.3390/nano7040074. PMid:28362331.

4. Vaia, R. A., \& Wagner, H. D. (2004). Framework for nanocomposites. Materials Today, 7(11), 32-37. http://dx.doi. org/10.1016/S1369-7021(04)00506-1.

5. Kumar, S. K., Benicewicz, B. C., Vaia, R. A., \& Winey, K. I. (2017). 50th anniversary perspective: are polymer nanocomposites practical for applications? Macromolecules, 50(3), 714-731. http://dx.doi.org/10.1021/acs.macromol.6b02330.

6. Malekzad, H., Zangabad, P. S., Mohammadi, H., Sadroddini, M., Jafari, Z., Mahlooji, N., Abbaspour, S., Gholami, S., Ghanbarpoor, M., Pashazadeh, R., Beyzavi, A., Karimi, M., \& Hamblin, M. R. (2018). Noble metal nanostructures in optical biosensors: Basics, and their introduction to anti-doping detection. Trends in Analytical Chemistry, 100, 116-135. http:// dx.doi.org/10.1016/j.trac.2017.12.006. PMid:29731530.

7. Liang, H., Wei, H., Pan, D., \& Xu, H. (2015). Chemically synthesized noble metal nanostructures for plasmonics. De Gruyter, 4(3), 289-302. http://dx.doi.org/10.1515/ntrev-2014-0026.

8. Jeevanandam, J., Barhoum, A., Chan, Y. S., Dufresne, A., \& Danquah, M. K. (2018). Review on nanoparticles and nanostructured materials: history, sources, toxicity and regulations. Beilstein Journal of Nanotechnology, 9, 10501074. http://dx.doi.org/10.3762/bjnano.9.98. PMid:29719757.

9. Conde, J., Doria, G., \& Baptista, P. (2012). Noble metal nanoparticles applications in cancer. Journal of Drug Delivery, 2012, 751075. http://dx.doi.org/10.1155/2012/751075. PMid:22007307.

10. West, J. L., \& Halas, N. J. (2000). Applications of nanotechnology to biotechnology: commentary. Current Opinion in Biotechnology, 11(2), 215-217. http://dx.doi.org/10.1016/S0958-1669(00)000823. PMid: 10753774.

11. Zeng, S., Baillargeat, D., Ho, H.-P., \& Yong, K.-T. (2014). Nanomaterials enhanced surface plasmon resonance for biological and chemical sensing applications. Chemical Society Reviews, 43(10), 3426-3452. http://dx.doi.org/10.1039/ c3cs60479a. PMid:24549396.

12. Safari, J., Najafabadi, A. E., Zarnegar, Z., \& Masoule, S. F. (2016). Catalytic performance in 4-nitrophenol reduction by Ag nanoparticles stabilized on biodegradable amphiphilic copolymers. Green Chemistry Letters and Reviews, 9(1), 2026. http://dx.doi.org/10.1080/17518253.2015.1134680.

13. Alshehri, S. M., Almuqati, T., Almuqati, N., Al-Farraj, E., Alhokbany, N., \& Ahamad, T. (2016). Chitosan based polymer matrix with silver nanoparticles decorated multiwalled carbon nanotubes for catalytic reduction of 4-nitrophenol. Carbohydrate Polymers, 151, 135-143. http://dx.doi.org/10.1016/j. carbpol.2016.05.018. PMid:27474552.

14. Chen, R., \& Whitmore, P. M. (2014). Silver nanoparticle films as hydrogen sulfide gas sensors with applications in art conservation. In A. S. Harper-Leatherman, \& C. M. Solbrig (Eds.), The science and function of nanomaterials: from synthesis to application (ACS Symposium Series; no. 1183; chap. 6; pp. 107-120). http://dx.doi.org/10.1021/bk-2014-1183.ch006.
15. Huff, C., Long, J. M., Aboulatta, A., Heyman, A., \& AbdelFattah, T. M. (2017). Silver nanoparticle/multi-walled carbon nanotube composite as catalyst for hydrogen production. ECS Journal of Solid State Science and Technology : JSS, 6(10), M115-M118. http://dx.doi.org/10.1149/2.0051710jss.

16. Guerra, F. D., Attia, M. F., Whitehead, D. C., \& Alexis, F. (2018). Nanotechnology for environmental remediation: materials and applications. Molecules (Basel, Switzerland), 23(7), 1760. http://dx.doi.org/10.3390/molecules23071760. PMid:30021974.

17. Khin, M. M., Nair, A. S., Babu, V. J., Murugan, R., \& Ramakrishna, S. (2012). A review on nanomaterials for environmental remediation. Energy \& Environmental Science, 5(8), 8075-8109. http://dx.doi.org/10.1039/c2ee21818f.

18. Martins, J. D. N., Freire, E., \& Hemadipour, H. (2009). Applications and market of PVC for piping industry. Polímeros: Ciência e Tecnologia, 19(1), 58-62. http://dx.doi.org/10.1590/ S0104-14282009000100014.

19. Liu, J., Su, Y., Peng, J., Zhao, X., Zhang, Y., Dong, Y., \& Jiang, Z. (2012). Preparation and performance of antifouling PVC/CPVC blend ultrafiltration membranes. Industrial \& Engineering Chemistry Research, 51(24), 8308-8314. http:// dx.doi.org/10.1021/ie300878f.

20. Bockhorn, H., Hornung, A., Hornung, U., \& Jakobstroer, P. (1998). New mechanistic aspects ofthe dehydrochlorination of PVC - application of dehydrochlorination to plastic mixtures and electronic scrap. Combustion Science and Technology, 134(1-6), 7-30. http://dx.doi.org/10.1080/00102209808924123.

21. Braga, L. R., Rangel, E. T., Suarez, P. A. Z., \& Machado, F. (2018). Simple synthesis of active films based on PVC incorporated with silver nanoparticles: evaluation of the thermal, structural and antimicrobial properties. Food Packaging and Shelf Life, 15, 122-129. http://dx.doi.org/10.1016/j.fps1.2017.12.005.

22. Thabet, A., \& Ebnalwaled, A. A. (2017). Improvement of surface energy properties of PVC nanocomposites for enhancing electrical applications. Measurement, 110, 78-83. http://dx.doi. org/10.1016/j.measurement.2017.06.023.

23. Broido, A. (1969). A simple, sensitive graphical method of treating thermogravimetric analysis data. Journal of Polymer Science. Part A-2, Polymer Physics, 7(10), 1761-1773. http:// dx.doi.org/10.1002/pol.1969.160071012.

24. Palem, R. R., Ganesh, S. D., Saha, N., Kronek, J., \& Sáha, P. (2018). 'Green' synthesis of silver polymer Nanocomposites of poly(2-isopropenyl-2-oxazoline-co-N vinylpyrrolidone) and its catalytic activity. Journal of Polymer Research, 25(7), 152. http://dx.doi.org/10.1007/s10965-018-1548-9.

25. Chang, M., Kim, T., Park, H.-W., Kang, M., Reichmanis, E., \& Yoon, H. (2012). Imparting chemical stability in nanoparticulate silver via a conjugated polymer casing approach. ACS Applied Materials \& Interfaces, 4(8), 4357-4365. http://dx.doi. org/10.1021/am3009967. PMid:22860984.

26. Kora, A. J., \& Rastogi, L. (2013). Enhancement of antibacterial activity of capped silver nanoparticles in combination with antibiotics, on model gram-negative and gram-positive bacteria. Bioinorganic Chemistry and Applications, 2013, 871097. http:// dx.doi.org/10.1155/2013/871097. PMid:23970844.

27. Aouachria, K., Massardier-Nageote, V., \& Belhaneche-Bensemra, N. (2014). Thermal stability and Kinetic Study of rigid and plasticized Poly(vinyl chloride)/Poly(methylmethacrylate) blends. Journal of Vinyl \& Additive Technology, 21(2), 102110. http://dx.doi.org/10.1002/vnl.21372.

28. Van Der Ven, S., \& De Wit, W. F. (1969). Thermal degradation of poly(vinyl chloride): the accelerating effect of hydrogen chloride. Die Angewandte Makromolekulare Chemie, 8(1), 143-152. http://dx.doi.org/10.1002/apmc.1969.050080110. 
29. Ganesh, S. D., Pai, V. K., Kariduraganavar, M. Y., \& Jayanna, M. B. (2014). Fluorinated poly(arylene ether-1,3,4-oxadiazole)s containing a 4-bromophenyl pendant group and its phosphonated derivatives: synthesis, spectroscopic characterization, thermal and dielectric studies. Polymer-Plastics Technology and Engineering, 53(1), 97-105. http://dx.doi.org/10.1080/0360 2559.2013.843694.

30. Peiris, T. A. N. (2014). Microwave-assisted processing of solid materials for sustainable energy related electronic and optoelectronic applications. Loughborough: Loughborough University.

31. Daněk, J., Klaiber, M., Hatsagortsyan, K. Z., Keitel, C. H., Willenberg, B., Maurer, J., Mayer, B. W., Phillips, C. R., Gallmann, L., \& Keller, U. (2018). Interplay between Coulombfocusing and non-dipole effects in strong-field ionization with elliptical polarization. Journal of Physics. B, Atomic, Molecular, and Optical Physics, 51(11), 114001. http://dx.doi. org/10.1088/1361-6455/aaba42.

32. Sidebottom, D. L., Roling, B., \& Funke, K. (2000). Ionic Conduction in Solids: Comparing Conductivity and Modulus Representations With Regard to Scaling Properties. Physical Review B: Condensed Matter, 63(2), 024301. http://dx.doi. org/10.1103/PhysRevB.63.024301.

33. Esumi, K., Isono, R., \& Yoshimura, T. (2004). Preparation of PAMAM- and PPI-Metal (Silver, Platinum, and Palladium) Nanocomposites and Their Catalytic Activities for Reduction of 4-Nitrophenol. Langmuir, 20(1), 237-243. http://dx.doi. org/10.1021/la035440t. PMid:15745027.

34. Murugan, E., \& Jebaranjitham, J. N. (2012). Synthesis and characterization of silver nanoparticles supported on surfacemodified poly( $\mathrm{N}$-vinylimidazale) as catalysts for the reduction of 4-nitrophenol. Journal of Molecular Catalysis A Chemical, 365, 128-135. http://dx.doi.org/10.1016/j.molcata.2012.08.021.

35. Liu, Y., Zhang, Y., Lan, Q., Liu, S., Qin, Z., Chen, L., Zhao, C., Chi, Z., Xu, J., \& Economy, J. (2012). High-Performance Functional Polyimides Containing Rigid Nonplanar Conjugated Triphenylethylene Moieties. Chemistry of Materials, 24(6), 1212-1222. http://dx.doi.org/10.1021/cm3003172.

36. Geng, Q., \& Du, J. (2014). Reduction of 4-nitrophenol catalyzed by silver nanoparticles supported on polymer micelles and vesicles. RSC Advances, 4(32), 16425-16428. http://dx.doi. org/10.1039/C4RA01866D.

37. Roy, A. S., Gupta, S., Seethamraju, S., Ramamurthy, P. C., \& Madras, G. (2014). Fabrication of Poly(Vinylidene ChlorideCo-Vinyl Chloride) $/ \mathrm{TiO}_{2}$ Nanocomposite Films and Their Dielectric Properties. Science of Advanced Materials, 6(5), 946-953. http://dx.doi.org/10.1166/sam.2014.1858.

Received: Dec. 07, 2018

Revised: May 24, 2019

Accepted: June 09, 2019 